\title{
Tonic Endovanilloid Facilitation of Glutamate Release in Brainstem Descending Antinociceptive Pathways
}

\author{
Katarzyna Starowicz, ${ }^{1 \star}$ Sabatino Maione, ${ }^{3 \star}$ Luigia Cristino, ${ }^{2}$ Enza Palazzo, ${ }^{3}$ Ida Marabese, ${ }^{3}$ Francesca Rossi,${ }^{3}$ \\ Vito de Novellis, ${ }^{3}$ and Vincenzo Di Marzo ${ }^{1}$ \\ ${ }^{1}$ The Endocannabinoid Research Group, Institute of Biomolecular Chemistry and "Institute of Cybernetics "E. Caianiello," Consiglio Nazionale delle \\ Ricerche, 80078 Pozzuoli, Naples, Italy, and 3Department of Experimental Medicine, Section of Pharmacology “L. Donatelli," Second University of Naples, \\ 80138 Naples, Italy
}

\begin{abstract}
Activation of transient receptor potential vanilloid-1 (TRPV1) channels in the periaqueductal gray (PAG) activates OFF antinociceptive neurons of the rostral ventromedial medulla (RVM). We examined in rats the effect of intra-ventrolateral (VL)-PAG injections of TRPV1 agonists and antagonists on the nocifensive response to heat in the plantar test, neurotransmitter (glutamate and GABA) release in the RVM, and spontaneous and tail flick-related activities of RVM neurons. The localization of TRPV1 in VL-PAG and RVM neurons was examined using various markers of glutamatergic and GABAergic neurons. Intra-VL-PAG injection of capsaicin increased the threshold of thermal pain sensitivity, whereas the selective TRPV1 antagonist 5' -iodo-resiniferatoxin (I-RTX) facilitated nociceptive responses, and blocked capsaicin analgesic effect at a dose inactive per se. Intra-VL PAG capsaicin evoked a robust release of glutamate in RVM microdialysates. I-RTX, at a dose inactive per se, blocked the effect of capsaicin, and inhibited glutamate release at a higher dose. Antinociception and hyperalgesia induced by capsaicin and I-RTX, respectively, correlated with enhanced or reduced activity of RVM OFF cells. Immunohistochemical analyses suggested that several TRPV1-immunoreactive (ir) neurons in both the VL-PAG and RVM are glutamatergic and surrounded by glutamatergic and GABAergic terminals. Our data suggest that VL-PAG neurons respond to TRPV1 stimulation by releasing glutamate into the RVM, thereby activating OFF cells and producing analgesia. The results obtained with the TRPV1 antagonist alone suggest that this pathway is tonically activated by endovanilloids.
\end{abstract}

Key words: TRPV1; pain; glutamate; periaqueductal gray; descending pathway; endovanilloid

\section{Introduction}

The crucial role of heat-activated transient receptor potential vanilloid-1 (TRPV1) channels in thermal hyperalgesia has been confirmed in TRPV $1{ }^{-} /^{-}$mice (Caterina et al., 2000). TRPV1 is well characterized in dorsal root ganglia and in sensory afferents involved in the pain pathway (Caterina et al., 1997), and its role in pain facilitation and pain transmission at the peripheral and spinal levels is well documented (Sasamura and Kuraishi, 1999; Maione et al., 2006a). Yet, data on the role of the TRPV1 in the supraspinal control of pain is still scant, despite the fact that increasing evidence demonstrates the expression of TRPV1 throughout the brain (Mezey et al., 2000; Sanchez et al., 2001; Roberts et al., 2004; Liapi and Wood, 2005; Toth et al., 2005; Cristino et al., 2006), including brainstem areas involved in the descending antinociceptive pathway, such as the periaqueductal gray (PAG) (McGaraughty et al., 2003; Cristino et al., 2006;

\footnotetext{
Received July 18, 2007; revised Sept. 24, 2007; accepted 0ct. 24, 2007.

We are grateful to Marco Allarà for valuable technical assistance.

*K.S. and S.M. contributed equally to this work.

Correspondence should be addressed to either Vincenzo Di Marzo or Sabatino Maione at the above addresses. E-mail:vdimarzo@icmib.na.cnr.it and sabatino.maione@unina2.it.

K. Starowiczs present address: Institute of Pharmacology, Polish Academy of Sciences, Department of Pain Pharmacology, 12 Smetna Street, 31343 Cracow, Poland.

D0I:10.1523/JNEUROSCI.3258-07.2007

Copyright $\odot 2007$ Society for Neuroscience ～0270-6474/07/2713739-11\$15.00/0
}

Maione et al., 2007). The PAG has a key role in the descending modulation of nociception (Behbehani, 1995; Fields, 2000), although this region has limited direct projections to the spinal cord (Sandkuhler and Gebhart, 1984), and uses the rostral ventromedial medulla (RVM), a site that projects directly to the spinal cord dorsal horn, as an important intermediate in pain modulation (Basbaum and Fields, 1984; Fields et al., 1995). Glutamate and GABA play a critical role in processing pain at the PAG-RVM level (Behbehani and Fields, 1979; Moreau and Fields, 1986; Harris and Hendrickson, 1987; Millan et al., 1987). Three different pain responding neuronal classes are found in the RVM (Fields et al., 1991): "neutral cells", which show no modification in spontaneous activity associated with nociceptive stimulation; ON cells, which show a burst of activity just before withdrawal reflexes; and OFF cells, which are inhibited just before withdrawal reflexes. These neurons respond in opposite ways to pharmacological stimulation with opioid receptor agonists: systemic or local injections of opioid receptor agonists sufficient to inhibit nociceptive reflexes inhibit ON cell and increase OFF cell activities (Fields et al., 1983; Heinricher and Tortorici, 1994; Fields, 2004).

Recently, it has been suggested that stimulation of TRPV1 receptors in the PAG increases the latency of nociceptive responses, by either acting on the same RVM-projecting neurons that mediate glutamate-induced analgesia in the PAG, or by de- 
sensitizing the activity of other neurons involved in glutamateinduced hyperalgesia in this region (Palazzo et al., 2002; McGaraughty et al., 2003). We hypothesized, based on pharmacological and electrophysiological data, that activation of excitatory neurons by an exogenous TRPV1 agonist in the ventrolateral (VL) PAG causes activation of OFF antinociceptive neurons of the RVM (Maione et al., 2006b). We also showed that pharmacological elevation in the brainstem of the levels of the endogenous agonist of cannabinoid and TRPV1 receptors, anandamide (Ross et al., 2001), obtained by using an inhibitor of its enzymatic hydrolysis, produces analgesia also via activation of TRPV1 receptors (Maione et al., 2006b). However, evidence that TRPV1 activation in the VL-PAG is coupled to glutamate release in the RVM is still missing. Therefore, we examined here in rats the effect of TRPV1 activation and antagonism on glutamatergic and GABAergic signaling in the VL-PAG-RVM circuit by studying their effect on: 1) nocifensive response to heat in the plantar test; 2) glutamate and GABA release in the RVM and 3) the spontaneous and tail flick-related activity of OFF and ON neurons of the RVM. Furthermore, we analyzed by immunohistochemistry the expression of TRPV1 in glutamatergic or GABAergic neurons in the PAG and RVM by using various markers.

\section{Materials and Methods}

Animals. Male Wistar rats (250-300 g) were housed 3 per cage under controlled illumination (12:12 h light/dark cycle; light on $06.00 \mathrm{~h})$ and environmental conditions (ambient temperature $20-22^{\circ} \mathrm{C}$, humidity $55-60 \%$ ) for at least 1 week before the start of the experiments. Rat chow and tap water were available ad libitum. The experimental procedures were approved by the Animal Ethics Committee of the Second University of Naples. Animal care was in compliance with Italian (D.L. 116/92) and EEC (O.J. of E.C. L358/1 18/12/86) regulations on the protection of laboratory animals. All efforts were made to minimize animal suffering and to reduce the number of animals used.

Surgical preparation for intra-PAG microinjections. To perform direct intra-VL PAG administrations of drugs or respective vehicle, $10 \%$ dimethylsulfoxide in artificial CSF (ACSF, composition in mM: $\mathrm{KCl} 2.5$; $\left.\mathrm{NaCl} 125 ; \mathrm{MgCl}_{2} 1.18 ; \mathrm{CaCl}_{2} 1.26\right)$, rats were anesthetized with pentobarbital ( $60 \mathrm{mg} / \mathrm{kg}$, i.p.) and a 31-gauge, $12 \mathrm{~mm}$-long stainless steel guide cannula was stereotaxically lowered until its tip was $1.5 \mathrm{~mm}$ above the ventrolateral PAG by applying coordinates from the atlas of Paxinos and Watson (1986) (AP: $-7.8 \mathrm{~mm}$ and L: $0.5 \mathrm{~mm}$ from bregma, V: $4.3 \mathrm{~mm}$ below the dura). Ventrolateral PAG (VL-PAG) was considered in this study, because previous studies have shown the presence of excitatory output neurons projecting to OFF neurons in the RVM in that area (Sandkulher and Gebhart, 1984; Moreau and Fields, 1986). The cannula was anchored with dental cement to a stainless steel screw in the skull. We used a David Kopf stereotaxic apparatus (David Kopf Instruments, Tujunga, CA, USA) with the animal positioned on a homeothermic temperature control blanket (Harvard Apparatus Limited, Edenbridge, Kent). Direct intra-VL PAG administration of drugs, or respective vehicle, was conducted with a stainless steel cannula connected by a polyethylene tube to a SGE $1 \mu$ l syringe, inserted through the guide cannula and extended $1.5 \mathrm{~mm}$ beyond the tip of the guide cannula to reach the VLPAG. Volumes of $200 \mathrm{nl}$ drug solutions, or vehicle, were injected into the VL PAG over a period of $60 \mathrm{~s}$ and the injection cannula gently removed 2 $\mathrm{min}$ later. At the end of the experiment, a volume of $200 \mathrm{nl}$ of neutral red $(0.1 \%)$ was also injected in the VL-PAG 30-40 min before killing the rat. Rats were then perfused intracardially with $20 \mathrm{ml}$ of PBS followed by 200 $\mathrm{ml}$ of $10 \%$ Formalin solution in PBS. The brains were removed and immersed in a saturated Formalin solution for $2 \mathrm{~d}$. The injection site was ascertained by using 2 consecutive sections $(40 \mu \mathrm{m})$, one stained with cresyl violet to identify nuclei and the other unstained to determine dye spreading. Only those rats whose microinjected site was located within the VL-PAG were used for data computation (see Fig. 3).

$R V M$ microdialysis. In vivo microdialysis experiments were performed in awake and freely moving rats. In brief, rats already implanted with guide cannula (as described above) and still anesthetized with pentobarbital $(60 \mathrm{mg} / \mathrm{kg}$, i.p.) were stereotaxically implanted with concentric microdialysis probes, which were constructed as previously described (Biggs et al., 1992), into the RVM using coordinates: AP: $-11.5 \mathrm{~mm}$ and L: $+0.3 \mathrm{~mm}$ from bregma, V: $10.5 \mathrm{~mm}$ below the dura (Paxinos and Watson, 1986). After a postoperative recovery period of $\sim 18 \mathrm{~h}$ dialysis was commenced by perfusing ACSF at a rate of $0.8 \mu \mathrm{l} / \mathrm{min}$ using a Harvard Apparatus infusion pump (model 22). On the day of the experiment each animal was placed in a Plexiglas cage and allowed to move freely. After an initial 60 min equilibration period, 12 consecutive 15 min dialysate samples were collected. On completion of each experiment, rats were anesthetized with pentobarbital and their brains perfused-fixed via the left cardiac ventricle with heparinized paraformaldehyde saline (4\%). Brains were removed after fixation, and coronal sections cut to verify probe placements (see Fig. 3). Dialysates were analyzed for amino acid content using an HPLC method. The system comprised two Gilson pumps (model 303), a C18 reverse-phase column, a Gilson refrigerated autoinjector (model 231) and a Gilson fluorimetric detector (model 121). Dialysates were precolumn derivatized with $o$-pthaldialdehyde (OPA) $(10 \mu \mathrm{l}$ of dialysate $+10 \mu \mathrm{l}$ of OPA) and amino acid conjugates resolved using a gradient separation. The detection limit of GABA and glutamate in $10 \mu \mathrm{l}$ samples was $\sim 0.5-1$ and $2-3$ pmol, respectively. The mobile phase consisted of two components: (A) $50 \mathrm{~mm}$ sodium dihydrogen orthophosphate, $\mathrm{pH} 5.5$, with 20\% methanol and (B) 100\% methanol. Gradient composition was determined with an Apple microcomputer installed with Gilson gradient management software. The mobile phase flow rate was maintained at $1.0 \mathrm{ml} / \mathrm{min}$. Data was collected using a Dell Corporation PC system 310 interfaced to the detector via a Drew data collection unit.

Thermal withdrawal latency during microdialysis. Thermal nociception was evaluated by using Plantar Test Apparatus (Ugo Basile, Varese, Italy). On the day of the experiment each animal, which had been previously implanted with a microdialysis probe, was placed in a plastic cage $(22 \times$ $17 \times 14 \mathrm{~cm}$; length $\times$ width $\times$ height) with a glass floor. After a $60 \mathrm{~min}$ habituation period, the plantar surface of the hind paw was exposed to a beam of radiant heat through the glass floor within the time interval between dialysate sample collection. The radiant heat source consisted of an infrared bulb (Osram halogen-bellaphot bulb; $8 \mathrm{~V}, 50 \mathrm{~W}$ ). A photoelectric cell detected light reflected from the paw and turned off the lamp when paw movement interrupted the reflected light. Paw withdrawal latency was automatically displayed to the nearest $0.1 \mathrm{~s}$; the cutoff time was $20 \mathrm{~s}$ to prevent tissue damage. Vehicle or drugs were microinjected into the PAG after the collection of five basal microdialysis samples and the simultaneous recording of five basal thermal withdrawal latencies every $30 \mathrm{~min}$. The results were expressed as percentage of the maximum possible effect using the following formula:

$$
\% \mathrm{MPE}=\frac{(\text { test latency })-(\text { control latency })}{(\text { cutoff time })-(\text { control latency })} \times 100
$$

Nociceptive responses were measured every $15 \mathrm{~min}$ for a period of $2 \mathrm{~h}$.

RVM extracellular recordings and tail flick test. After implantation of the guide cannula into the VL-PAG (described in: Surgical preparation for intra-PAG microinjections), a tungsten microelectrode was stereotaxically lowered through a small craniotomy into the RVM (AP: 11.5; L: + 0.3; V: 9.9-10.9) (Paxinos and Watson, 1986) to record the activity of Neutral, ON and OFF cells (see Fig. 3). These neurons were identified by the characteristic OFF cell pause and ON cell burst of activity just before tail flick responses (Fields et al., 1983). Anesthesia was maintained with a constant, continuous infusion of propofol (5-10 mg/kg/h, i.v.). Anesthesia was adjusted so that tail flicks were elicited with a constant latency of $4-5 \mathrm{~s}$. A thermal stimulus was elicited by a radiant heat source of a tail flick unit (Ugo Basile, Varese, Italy) focused on the rat tail $\sim 3-5 \mathrm{~cm}$ from the tip. From $35^{\circ} \mathrm{C}$, the temperature increased linearly to $53^{\circ} \mathrm{C}$ and was adjusted at the beginning of each experiment to elicit a constant tail flick latency. Tail flicks were elicited every 3-4 min for at least 15-20 min before microinjecting drugs, or respective vehicle, into the VL-PAG.

Extracellular single-unit recordings were made in the RVM with glass insulated tungsten filament electrodes (3-5 M $\Omega$ ) (Frederick Haer Com- 
pany, Bowdoinham, ME). The recorded signals were amplified and displayed on analog and digital storage oscilloscope to ensure that the unit under study was unambiguously discriminated throughout the experiment. Signals were also fed into a window discriminator, whose output was processed by an interface (CED 1401) (Cambridge Electronic Design, Cambridge, UK) connected to a Pentium III PC. Spike2 software (version 4; Cambridge Electronic Design) was used to create peristimulus rate histograms on-line and to store and analyze digital records of singleunit activity off-line. Configuration, shape, and height of the recorded action potentials were monitored and recorded continuously, using a window discriminator and Spike2 software for on-line and off-line analysis. Once an ON or OFF cell was identified from its background activity, we optimized spike size before all treatments. This study only included neurons whose spike configuration remained constant and could clearly be discriminated from activity in the background throughout the experiment, indicating that the activity from one neuron only and from that same neuron was measured. Only one neuron was recorded in each rat.

Immunohistochemistry. Animals were deeply anesthetized with pentobarbital and perfused transcardially with saline followed by ice-cold $4 \%$ paraformaldehyde in $0.1 \mathrm{M}$ phosphate buffer $(\mathrm{PB}), \mathrm{pH}$ 7.4. Brains were removed, postfixed for $2 \mathrm{~h}$ and then washed. Tissues to be cut at cryostat were cryoprotected overnight in PB containing $30 \%(\mathrm{w} / \mathrm{v})$ sucrose at $4^{\circ} \mathrm{C}$ until they sank. Serial cryostat sections were cut at $14 \mu \mathrm{m}$ and mounted onto gelatin-coated slides (Mezel, Germany). For double immunofluorescence serial sections were incubated for $1 \mathrm{~h}$ in $10 \%$ normal donkey serum (NDS, Jackson Immunoresearch Laboratories, West Grove, PA) in PB containing $0.3 \%$ Triton X-100 (block solution). Subsequently the sections were incubated for $2 \mathrm{~d}$ at $4^{\circ} \mathrm{C}$ in a humid chamber with the respective polyclonal antibodies (all diluted in block solution). All sections were processed for anti-TRPV1 receptor immunoreaction (1:250 guinea pig anti-TRPV1, Abcam, Cambridge, UK) coupled to one of the following: rabbit anti-vesicular glutamate transporter-1 (VGLUT1) (1: 500, SySy, Germany), rabbit anti-vesicular GABA transporter (VGAT) (1:250, SySy, Germany), rabbit-anti metabotropic glutamate receptor 7 (mGluR7) (1:500, Chemicon International, Germany) or rabbit anti- $\mu$ opioid receptor (MOR) (1:1000, Abcam, Cambridge, UK). After three washes in $\mathrm{PB}$, double immunofluorescence was revealed by incubation for $2 \mathrm{~h}$ in the appropriate fluorochrome conjugated secondary antibody: Alexa Fluor488 anti guinea pig (for TRPV1); Alexa Fluor546 anti rabbit (for VGLUT1, VGAT, mGluR7 and MOR) diluted 1:250 in NDS block solution. Thereafter, sections were washed with $\mathrm{PB}$ and coverslipped with Aquatex mounting medium (Merck, Darmstadt, Germany).

Controls included (1) preabsorption of diluted antibodies with their respective immunizing peptides (if not commercially available control peptides were synthesized on custom request by Inbios, Italy), and (2) omission of either the primary antisera or the secondary antibodies. These control experiments did not show staining. The sections processed for immunofluorescence were studied with an epifluorescence microscope (Leica DM IRB); settings for excitation of fluorescein isothiocyanate $(488 \mathrm{~nm})$ and Texas Red $(543 \mathrm{~nm})$ were identical throughout the analysis. Images were acquired using the digital camera Leica DFC 320 connected to the microscope and the image analysis software Leica IM500, which allows both single and merged pictures acquisitions. Digital images were processed in Adobe Photoshop, with brightness and contrast being the only adjustments made.

Quantification of immunoreactivity. Quantification of the mean percentage value of the number of neurons double-labeled for TRPV1/ VGLU1 or TRPV1/VGAT or TRPV1/mGluR7 or TRPV1/MOR was performed by an observer blinded to the experimental protocols, on the total of VL-PAG and RVM neurons identified with respect to the corresponding adjacent section labeled with cresyl violet and whose nuclei, unstained or lightly stained, were in the focal plane. The level of section evaluated for immunohistochemistry study covered the entire extension of the VL-PAG or RVM regions, approximately for $1.0 \mathrm{~mm}$ rostrally from bregma AP:- $8.0 \mathrm{~mm}, \mathrm{~L}: 0.5 \mathrm{~mm}$ and AP:- $12.0 \mathrm{~mm}$, L:+0.3 mm respectively. For each regions we counted 9 section per animal ( 4 animals per group) for each double immunolabeling.

Experimental technique combination. In vivo single-unit electrophysiological recording was coupled to tail flick latency monitoring in lightly anesthetized rats to identify ON, OFF, and NEUTRAL cells. Microdialysis was coupled to Hargreaves' method (Plantar Test) to correlate PAG amino acid release to behavioral pain responses in awake freely moving rats.

Treatments. Groups of 8-10 animals per treatment were used with each animal being used for one treatment only.

For the combined plantar test and RVM microdialysis experiments, rats received intra-VL PAG microinjections of vehicle, capsaicin (6 $\mathrm{nmol} / \mathrm{rat})$, I-RTX ( 0.1 and $0.5 \mathrm{nmol} / \mathrm{rat})$ alone or I-RTX $(0.1 \mathrm{nmol} / \mathrm{rat})$ in combination with capsaicin $(6 \mathrm{nmol} / \mathrm{rat})$.

For in vivo extracellular recording and tail-flick test, rats received intra-VL-PAG microinjections of vehicle, capsaicin (3 and $6 \mathrm{nmol} / \mathrm{rat}$ ), I-RTX ( 0.5 and $1 \mathrm{nmol} / \mathrm{rat})$ alone or I-RTX $(0.5 \mathrm{nmol} / \mathrm{rat})$ in combination with capsaicin $(6 \mathrm{nmol} / \mathrm{rat})$.

An important issue regards how we chose the doses of capsaicin or I-RTX to be administered into the VL-PAG. The choice was based on our and others' previous in vivo studies in the rat (Palazzo et al., 2002; McGaraughty et al., 2003). Indeed, we performed extensive preliminary experiments with several doses of capsaicin, as well as of I-RTX, to find minimal doses able to change RVM cell activities or thermoceptive thresholds.

Drugs. Capsaicin and I-RTX (5'-Iodo-resiniferatoxin) were purchased from Tocris Cookson Ltd, Bristol, UK.

Drugs were dissolved in 10\% dimethylsulfoxide in ACSF with final $\mathrm{pH}=7.2$ for intra-VL PAG microinjections.

Statistics. Single-unit extracellular recording (action potentials) was analyzed off-line from peristimulus rate histograms using Spike2 software (CED, version 4). The neuron responses, before and after intra-VLPAG vehicle or drug microinjections, were measured and expressed as spikes/s (Hz). Baseline activities of neurons were measured between tail flicks. In particular, basal values were obtained by averaging the activities recorded $30-50 \mathrm{~s}$ before the application of 3-4 thermal stimulations (each stimulation trial was performed every 3-4 min). Data are presented as mean \pm SE either of changes in time latencies (tail flick test) or changes in neuron responses (extracellular recordings). Statistical comparisons of values from different treated groups of rats were made using the two-way ANOVA for repeated measures followed by the TukeyKramer test for post hoc comparisons.

To analyze tail flick-related ON cell activities (before and after drug treatment), the ongoing activity (spikes/s) was determined $30-50 \mathrm{~s}$ before tail flick application, and then the peak of ON cell activity related to the tail flick (peak firing) was quantified. Tail flick-related ON cell firing was calculated as the number of spikes in the $2 \mathrm{~s}$ interval beginning $0.5 \mathrm{~s}$ before the tail flick. Comparisons between pretreatment and posttreatment ongoing activity and tail flick-related cell burst were performed by applying the nonparametric Wilcoxon matched-pairs signed rank test. Furthermore, we calculated the ON cell burst latency; that is, the interval between the onset of the applied noxious radiant heat and the beginning of the tail flick-related cell burst. Burst latency was analyzed using twoway ANOVA for repeated measures followed by the Tukey-Kramer test for post hoc comparisons.

We also performed analysis of tail flick related OFF cell activities before and after drug treatments. The ongoing activity (spikes/s, 40-50 s before radial heat application), the latency to onset of the OFF cell pause (the interval between the onset of thermal stimulus and the last spike), and the duration of the cell pause (the interval between the pause onset and the first spike after the tail flick) were determined. Comparisons between pretreatment and posttreatment ongoing activity and cell pause related to tail flick were performed by applying the nonparametric Wilcoxon matched-pairs signed rank test. The interval between the onset of applied noxious radiant heat and the beginning of the tail flick related cell pause (pause latency), was also calculated. The latency to the onset of the cell pause was analyzed with a two-way ANOVA for repeated measures with the Tukey-Kramer test for post hoc comparisons.

Microdialysis, tail flick or plantar test data are represented as means \pm SEM, and statistical analysis of these data were performed by two-way ANOVA for repeated measures followed by the Student-Newman-Keuls multiple comparisons test to determine the statistical significance be- 

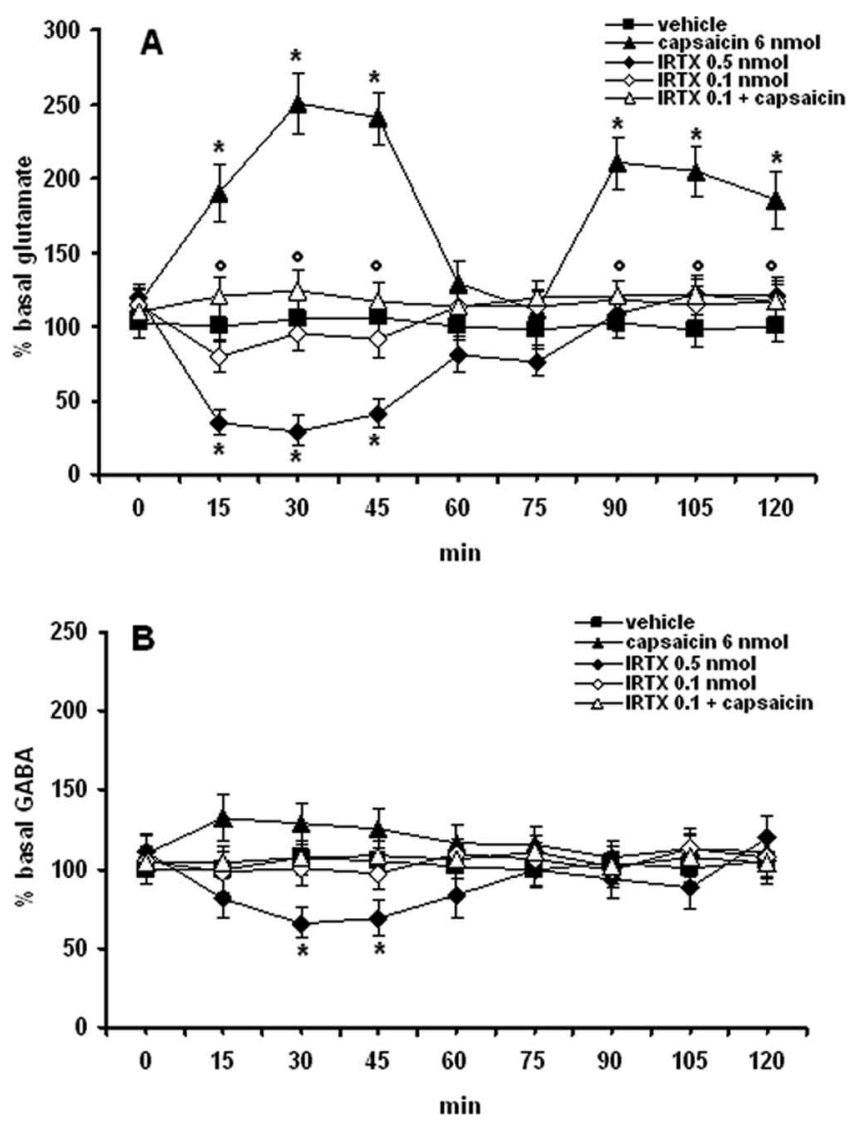

Figure 1. Effects of intraventrolateral PAG injection of vehicle, capsaicin ( $6 \mathrm{nmol} / /$ rat), I-RTX ( 0.1 and $0.5 \mathrm{nmol} / \mathrm{rat})$, and capsaicin $(6 \mathrm{nmol} / / \mathrm{rat})$ in combination with I-RTX $(0.1 \mathrm{nmol} / / \mathrm{rat})$ on RVM dialysate levels of glutamate $(\boldsymbol{A})$ and GABA $(\boldsymbol{B})$. Each point represents the mean \pm SEM of amino acid extracellular concentrations as a percentage of the basal values $(8-10$ rats per group). ${ }^{*}$ indicates significant difference versus vehicle; ${ }^{\circ}$ indicates significant difference versus capsaicin $(6 \mathrm{nmol} / \mathrm{rat})$. $p$ values $<0.05$ were considered statistically significant.

tween different treated groups of rats. Differences were considered significant at $p<0.05$.

\section{Results}

Effect of vehicle on RVM glutamate and GABA extracellular values

The mean basal extracellular GABA and glutamate levels in the RVM (not corrected for probe recovery of $21 \pm 6$ and $26 \pm 6 \%$ for GABA and glutamate, respectively) were $5.8 \pm 0.6$ and $19.5 \pm$ $6.2 \mathrm{pmol} / 10 \mu \mathrm{l}$ of dialysate (mean $\pm \mathrm{SEM}$ ), respectively. Each animal was used only once and the reported basal values of glutamate and GABA are the mean concentrations obtained from all experiments pooled as controls.

\section{Effect of capsaicin and I-RTX on RVM glutamate and GABA extracellular values}

Intra-VL-PAG microinjection with the TRPV1 receptor agonist, capsaicin $(6 \mathrm{nmol} / \mathrm{rat})$ increased significantly $(p<0.05)$ the extracellular levels of glutamate in the RVM (Fig. $1 A$ ). A biphasic increase of levels of glutamate was observed after intra-VL PAG injection of capsaicin: glutamate levels augmented (178 $\pm 9 \%$ of basal value) already after $15 \mathrm{~min}$ from its injection and returned to the basal level after $60 \mathrm{~min}$. Thereafter a subsequent increase of the levels of glutamate ( $207 \pm 8 \%$ of basal value) was observed 90 min after capsaicin injection. Capsaicin $(6 \mathrm{nmol} / \mathrm{rat})$ only slightly increased dialysate GABA concentration $(123 \pm 12 \%$ of basal value, $15 \mathrm{~min}$ after its injection) (Fig. $1 \mathrm{~B}$ ). At the higher dose

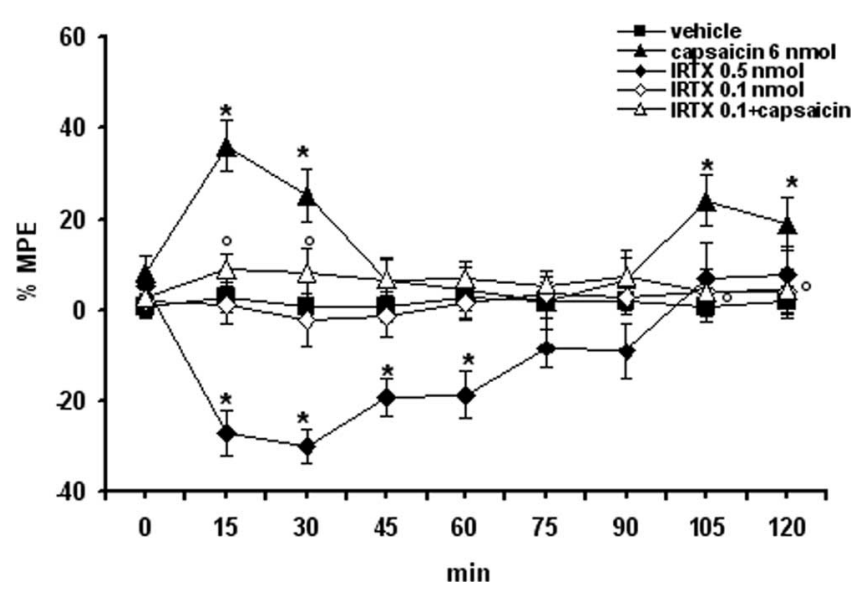

Figure 2. Thermal nociception was evaluated by using a plantar test and expressed as percentage of the maximum possible effect: \%MPE $=[$ (test latency) - (control latency)/(cutoff time) - (control latency) $\times 100$. Vehicle (10\% DMSO in ACSF), capsaicin $(6 \mathrm{nmol} / \mathrm{rat}), \mathrm{I}-\mathrm{RTX}$ ( 0.1 and $0.5 \mathrm{nmol} / \mathrm{rat})$, and capsaicin $(6 \mathrm{nmol} / \mathrm{rat})$ in combination with I-RTX $(0.1 \mathrm{nmol} / \mathrm{rat})$ were microinjected into the ventrolateral PAG. Nociceptive responses were measured every 15 min for a period of $2 \mathrm{~h}$. Each data point represents the mean \pm SEM of 8-10 animals per group. * indicates significant differences versus vehicle; ${ }^{\circ}$, indicates significant differences versus capsaicin $(6 \mathrm{nmol} / \mathrm{rat})$. $p$ values $<0.05$ were considered statistically significant.

tested I-RTX (0.5 nmol/rat), a selective TRPV1 receptor antagonist, evoked a significant decrease of glutamate ( $66 \pm 7 \%$ of basal value, $15-45-$ min after injection) and a very small albeit still significant decrease of GABA ( $38 \pm 6 \%$ of basal value, $30-45$ min after injection). I-RTX, at a dose $(0.1 \mathrm{nmol} / \mathrm{rat})$ that did not significantly change the release of glutamate and GABA, antagonized the effect induced by capsaicin on extracellular glutamate release (Fig. $1 A$ ).

\section{Effect of capsaicin and I-RTX on thermal nociception}

Microinjections of capsaicin ( $6 \mathrm{nmol} / \mathrm{rat})$, a vanilloid TRPV1 receptor agonist, into the VL-PAG produced a significant $(p<$ $0.05)$ and immediate increase in the latency of the nociceptive reaction of $38 \pm 7$ and $26 \pm 6 \%$ (Fig. 2), 15 and 30 min after its injection, respectively. A delayed analgesia was also observed, following 105 and $120 \mathrm{~min}$ after intra-VL-PAG capsaicin injection ( $22 \pm 7$ and $18 \pm 5 \%$, respectively). Microinjection of I-RTX ( $0.5 \mathrm{nmol} / \mathrm{rat})$, a selective TRPV1 receptor antagonist caused a decrease of the latency of the nociceptive reaction in the plantar test $(p<0.05)$ up to $60 \mathrm{~min}$ after its administration. Capsaicininduced antinociception was significantly prevented by I-RTX $(0.1 \mathrm{nmol} / \mathrm{rat})(p<0.05)$, a dose which did not modify per se the latency of the nociceptive reaction (Fig. 2). Vehicle alone did not change per se the latency of the nociceptive reaction (Fig. 2). To exclude capsaicin diffusing to other sites, microinjections of capsaicin were intentionally performed $1 \mathrm{~mm}$ away from the VL PAG. These latter injections were not able to significantly modify the latency of the nociceptive reaction (data not shown). Despite the evidence that the PAG is a key site in integrating the aversive behavior in this current study, we did not observe any characteristic behavioral changes in response to capsaicin microinjections at the doses used.

\section{Effect of capsaicin and I-RTX on the ongoing activities of RVM Neutral, ON and OFF cells}

The results are based on RVM neurons (group size $=8-10$; one cell recorded from each animal per treatment) at a depth $9900-$ $10,955 \mu \mathrm{m}$ from the surface of the brain, the estimated location of 


\section{A}

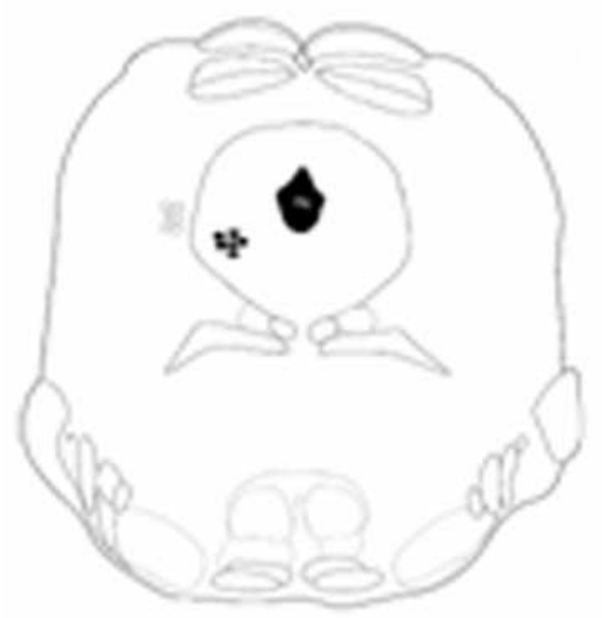

100

\section{B}

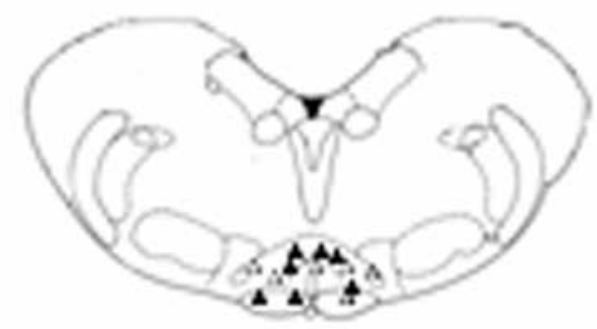

$-200$
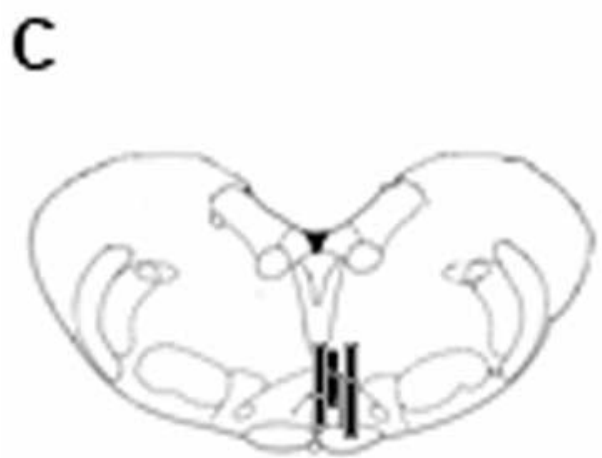

$-200$

Figure 3. Schematic illustration of the location of PAG microinjection sites (A), RVM ON- or OFF-cell recording sites $(\boldsymbol{B})$, and RVM microdialysis probes location ( $\boldsymbol{C}$. Vehicle or drug microinjections were performed into the ventrolateral PAG matter (filled circles) $(\boldsymbol{A})$ while cell recording was performed by lowering a tungsten electrode into the RVM (B). Filled triangles represent ON-cells and open triangles the OFF-cell sites. The location of microdialysis probe $(\boldsymbol{C})$ was also histologically confirmed and marked as correct (black bars) when the probe tip fell within the RVM areas here studied. Many sites are not shown because of overlap of symbols. Distances from the interaural line are indicated. the neurons being in nucleus raphe magnus, nucleus reticularis gigantocellularis pars $\alpha$, and nucleus reticularis paragigantocellularis (Fig. 3). All recorded neurons were spontaneously active and discharged with a mean frequency of $7.4 \pm 0.7$ (ON cells) and $8.7 \pm 1.1$ (OFF cells) spikes/s. These neurons were identified by the characteristic OFF cell pause and ON cell burst of activity just before tail flick responses. Microinjections of capsaicin at the lower dose $(3 \mathrm{nmol} / \mathrm{rat})$ did not cause any significant effect, whereas capsaicin at dose of $6 \mathrm{nmol} / \mathrm{rat}$ caused a decrease in the firing activity of the ON cells, which was significant between 3 and $24 \mathrm{~min}$, and maximal between 6 and $12 \mathrm{~min}$ after administration of the higher dose (Figs. 4A, 5A). The same treatment produced a very rapid increase in the firing activity of the OFF cells, which was maximal 9 min after the administration of the higher dose of capsaicin (Figs. $4 B, 5 B)$. I-RTX $(0.5 \mathrm{nmol} / \mathrm{rat}$ ) was inactive per se but, at a higher dose $(1 \mathrm{nmol} / \mathrm{rat})$, increased the firing activity of $\mathrm{ON}$ cells, an effect which was significant between 3 and 12 min (Figs. 4C,D, 5C,D). I-RTX (1 nmol/rat) decreased very rapidly the firing activity of the OFF cells, an effect significant between 3 and $12 \mathrm{~min}$ after the administration of the higher dose (Figs. $4 D, 5 D$ ). The effects of capsaicin were prevented by pretreatment with I-RTX $(0.5 \mathrm{nmol} / \mathrm{rat})$, a dose which did not significantly change per se the RVM ON and OFF cell ongoing activities (Fig. $4 A, B$ ). Spontaneous activities of RVM neutral neurons $(n=5)$ as identified by their nonresponsiveness to tail flick were also analyzed before and after intra-VL-PAG microinjections of capsaicin or I-RTX. Both drug treatments failed to cause any change in their spontaneous activities (data not shown).

\section{Effect of capsaicin and I-RTX on tail flick-related RVM ON and OFF cell activities}

The highest doses of capsaicin and I-RTX modified tail flickrelated $\mathrm{ON}$ and $\mathrm{OFF}$ cell activities. Capsaicin $(6 \mathrm{nmol} / \mathrm{rat})$ did not significantly change the $\mathrm{ON}$ cell onset of burst ( $3.6 \pm 0.6$ vs $4.1 \pm$ $0.5 \mathrm{~s}$ ), whereas it decreased the OFF cell pause (from $10.4 \pm$ $3.2-4.2 \pm 0.5 \mathrm{~s})(p<0.05)$. Capsaicin also decreased tail flickinduced ON cell peak firing (from 16.9 $\pm 4.2-7.2 \pm 2.1$ spikes/s), whereas it delayed the onset of OFF cell pause (from $4.1 \pm 0.5-$ $7.8 \pm 0.4 \mathrm{~s})(p<0.05)$. I-RTX $(1 \mathrm{nmol} / \mathrm{rat})$ did not significantly change the ON cell onset of burst ( $3.6 \pm 0.6 \mathrm{vs} 4.5 \pm 0.7 \mathrm{~s}$ ), but it increased the duration of the OFF cell pause (from $11.8 \pm 3.6-$ $19.6 \pm 3.5$ s) $(p<0.05)$. I-RTX did not significantly change tail flick-induced ON cell peak firing (from $16.9 \pm 4.2-12.1 \pm 2.5$ spikes/s), but shortened the onset of OFF cell pause (from $4.1 \pm$ $0.5-2.3 \pm 0.3 \mathrm{~s})(p<0.05)$. Unlike RVM ON and OFF cells, the administration of capsaicin or I-RTX did not affect the activity of neutral cells before and after thermoceptive stimuli (data not shown). Figure 5 shows rate histograms derived from example RVM ON- and OFF-neurons before and after drug microinjections.

\section{Effect of capsaicin and I-RTX on tail-flick latencies}

Tail flicks were elicited every 3-4 min for at least $20 \mathrm{~min}$ before microinjecting drugs, or respective vehicle, into the VL-PAG. Data related to pretreatment interval were considered as basal tail flick latencies ( $4.7 \pm 0.4 \mathrm{~s}$ ). Intra-VL-PAG microinjection of vehicle did not change the tail flick latency compared with basal values ( $4.5 \pm 0.6 \mathrm{~s})$ (Fig. 6). Tail flick latency was increased to $10.6 \pm 0.5 \mathrm{~s}$ or decreased to $2.2 \pm 0.4 \mathrm{~s}$ by intra-VL-PAG microinjections of capsaicin $(6 \mathrm{nmol} / \mathrm{rat})$ or I-RTX $(1 \mathrm{nmol} / \mathrm{rat})$, respectively $(p<0.05)$ (Fig. $6 A, B)$. Both capsaicin and I-RTX at lower doses tested were inactive per se $(3$ and $0.5 \mathrm{nmol} / \mathrm{rat}$, re- 
spectively) (Fig. 6A, $B$ ). The effect of the higher dose of capsaicin was prevented by pretreatment with an inactive dose of I-RTX (0.5 nmol/rat) (Fig. 6A).

\section{Localization of TRPV1 in neurons of the rat PAG and RVM}

Immunohistochemical localization of TRPV1 receptor in rat PAG and RVM was determined by immunofluorescence (Figs. 7, 8). We found TRPV1 positive neurons in the PAG area. A high density $(42 \pm 4 \%)$ of TRPV1 positive profiles with strong immunoreactivity (ir) was observed within the ventrolateral subregion. In the VLPAG, TRPV1 was mostly found in cell bodies (Fig. $7 A, D$ ). In PAG high density $(96 \pm 3 \%)$ of vesicular glutamate transporter 1 (VGLUT1)-ir on nerve terminals (Fig. $7 B, E$ ) surrounding TRPV1 positive cells indicate glutamatergic input on TRPV1-ir cells (Fig. 7C). In VL-PAG, many fibers were also vesicular GABA transporter (VGAT) positive (Fig. $7 E$ ), and VGAT-ir was observed around $92 \pm 6 \%$ TRPV 1 positive cells (Fig. $7 F$ ), thus demonstrating that TRPV1-ir neurons receive GABAergic inputs as well. Expression of TRPV1 in the RVM was found in $36 \pm 5 \%$ of the cell bodies (Fig. $8 A, D$ ).

In the RVM VGAT staining profile (Fig. $8 E$ ) was similar to that one observed in VL PAG, with $21 \pm 3 \%$ of TRPV1 labeled cells being surrounded by VGAT-positive nerve terminals and $80 \pm 7 \%$ of them expressing also VGLUT1 (Fig. 8 F). VGLUT1 in the RVM did not label only nerve fibers and terminals, but also several RVM cell bodies (Fig. 8 B). By means of double immunofluorescence we identified several TRPV1/VGLUT1 positive cells in the RVM (Fig. 8C). Although VGLUT1 is rapidly trafficked to presynaptic terminals after its biosynthesis, the rate of this process might be lower in some neurons, especially in the RVM neurons in which, compared with VL-PAG neurons, the ongoing activities of $\mathrm{ON}$ and OFF cells (many of which are quiescent under nonpronociceptive conditions) are generally of low frequency. Because synaptic protein trafficking is often activitydependent (Davis et al., 1998; Fournier et al., 2004), this might explain our finding of VGLUT-ir in RVM, but not VL-PAG, perikarya.

Double TRPV1/mGluR7 immunofluorescence showed an intense coexpression in neurons of VL-PAG (Fig. 9A-C) and RVM as well (Fig. 9D-F). Moreover double TRPV1/MOR immunoreactivity colocalized in a $97 \pm 2 \%$ of cell bodies of VL-PAG neurons (Fig. $9 G-I$ ) and in $84 \pm 5 \%$ of RVM neurons (Fig. 9J-L).

\section{Discussion}

In the present study we investigated the potential TRPV1mediated facilitation of the release of glutamate, an excitatory neurotransmitter, in the VL-PAG/RVM descending antinociceptive pathway. TRPV1 is involved in the tonic processing of multiple nociceptive stimuli at the level of both DRG and sensory nerve endings (Caterina et al., 2000; Davis et al., 2000), and might play a role also in the supraspinal and central control of nociception (Cui et al., 2006). At the supraspinal level, the PAG interacts with several brainstem structures to modulate nociception (Westlund et al., 1983; Kalyuzhny et al., 1996). Of these, the RVM is the principal relay in the integration of ascending nociceptive

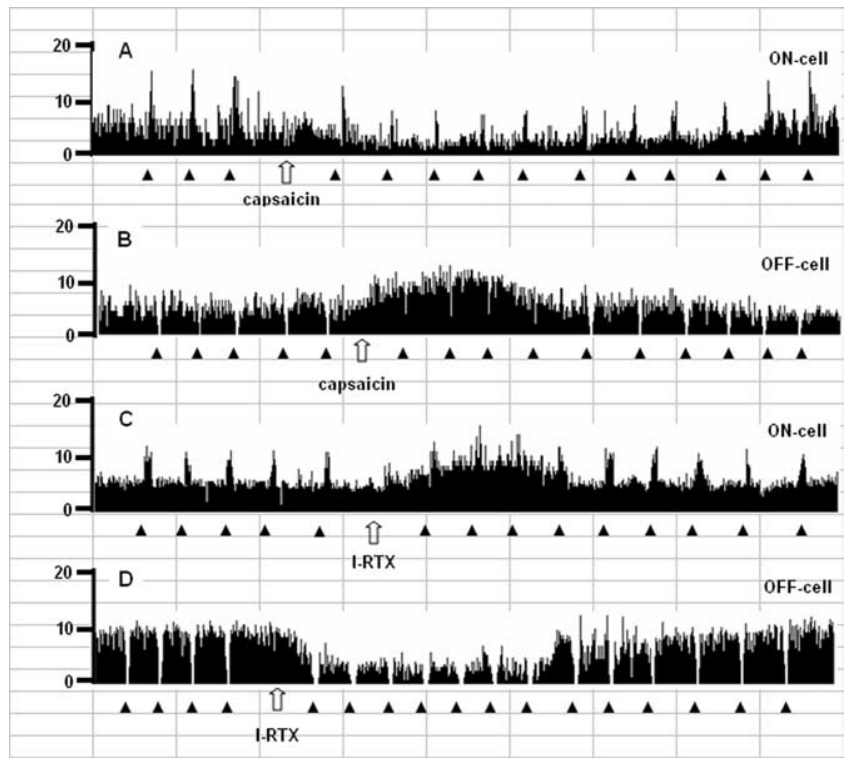

Figure 5. Examples of ratemeter records that illustrate the effects of intra-PAG microinjections of capsaicin ( $6 \mathrm{nmol} / \mathrm{rat})(\boldsymbol{A}, \boldsymbol{B})$ or I-RTX (1 nmol/rat) $(\boldsymbol{C}, \boldsymbol{D})$ on either the ongoing or tail flick-related discharges of identified RVM ON $(\boldsymbol{A}, \boldsymbol{C})$ and OFF $(\boldsymbol{B}, \boldsymbol{D})$ cells. Traces report overall firing before and after drug injections into the ventrolateral PAG. Filled triangles indicate tail flick trials, $1 \mathrm{~s}$ bins. Open arrows show the time of microinjections within the ventrolateral PAG. Time units, 1 cell $=7 \mathrm{~min}$.

inputs with descending outputs from rostral sites (Fields, 2004; Fields et al., 2005), as well as the major source of bulbospinal projections that terminate in laminas I, II and V of the dorsal horn, mostly via OFF and ON cells (see Introduction). We recently hypothesized the existence of excitatory neurons of the VL-PAG that respond to TRPV1 stimulation by activating RVM OFF neurons and producing analgesia (Maione et al., 2006b). Here, we gain support to this hypothesis, and suggest that these excitatory neurons are glutamatergic. By combining plantar test and in vivo microdialysis in freely moving rats we determined the effect of TRPV1 receptor activation and blockade not only on 

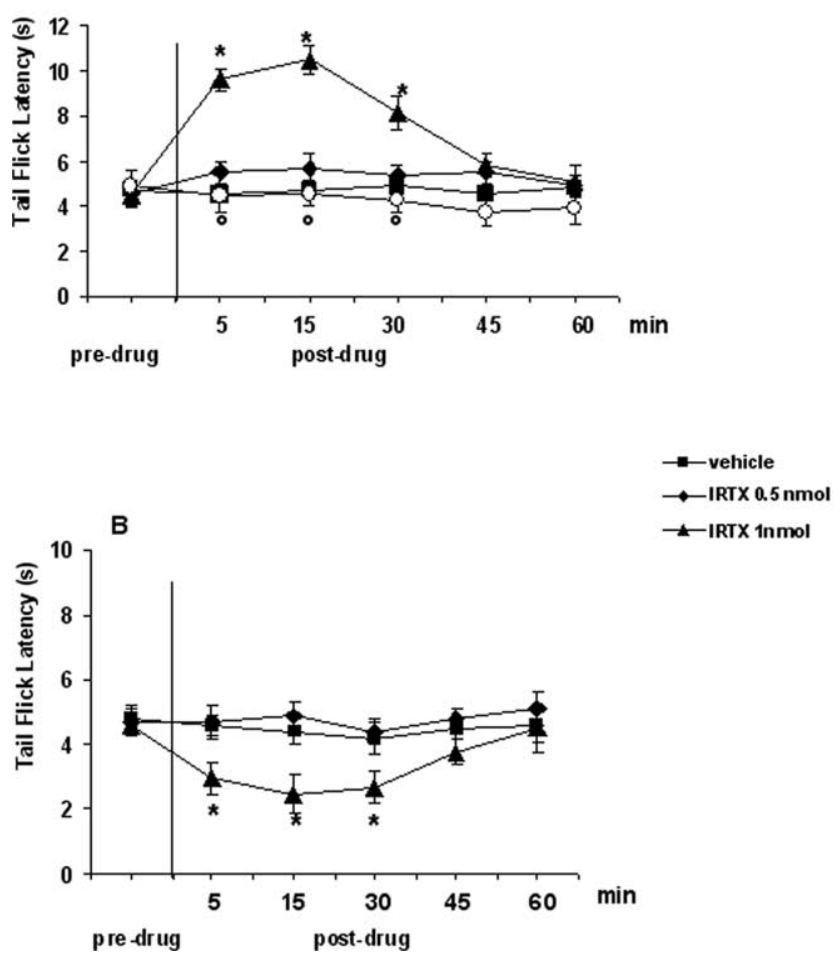

Figure 6. Tail flick latencies before and after microinjections into the ventrolateral PAG of vehicle, capsaicin ( 3 and $6 \mathrm{nmol} / \mathrm{rat}$ ) alone or in combination with I-RTX $(0.5 \mathrm{nmol} / \mathrm{rat})(\boldsymbol{A})$, and vehicle or I-RTX (0.5 and $1 \mathrm{nmol} / \mathrm{rat})(\boldsymbol{B})$. Each point represents the mean $\pm \mathrm{SEM}$ of 8-10 observations. * indicates significant differences versus vehicle; ${ }^{\circ}$ indicates significant differences versus capsaicin ( $6 \mathrm{nmol} / \mathrm{rat}$ ). $p$ values $<0.05$ were considered statistically significant.

nocifensive behavior but also on the concomitant release in the RVM of glutamate and GABA, two neurotransmitters that deeply affect nociceptive perception (Gebhart et al., 1984). Capsaicin injection into the VL-PAG increased the threshold of thermal pain sensitivity in healthy rats, whereas the selective TRPV1 antagonist I-RTX facilitated nociceptive responses, and at a per se inactive dose abolished capsaicin-mediated antinociception, thus suggesting that the effect of capsaicin was mediated by TRPV1 receptors. The effect of intra-VL PAG capsaicin was accompanied by robust glutamate release in RVM microdialysates, which was again blocked by a per se inactive dose of I-RTX. The TRPV1 antagonist, instead, decreased the release of glutamate, thus suggesting that VL-PAG TRPV1 receptors and endogenous compounds capable of activating them, known as "endovanilloids" (Starowicz et al., 2007), tonically stimulate glutamatergic output to the RVM, and concomitantly inhibit nociception in the VLPAG-RVM pathway. A likely candidate for this role is anandamide (Zygmunt et al., 1999), as suggested by our previous finding of TRPV1-mediated antinociception after intra-VL-PAG injection of a selective inhibitor of anandamide enzymatic hydrolysis (Maione et al., 2006b). However, also $N$-acyl-dopamines (Huang et al., 2002; Chu et al., 2003) and products of lipoxygenases (12and 15-(S)-HPETE) (Hwang et al., 2000) activate TRPV1 receptors (Starowicz et al., 2007). Our present finding of TRPV1mediated activation and inhibition of RVM OFF and ON neurons, respectively, after intra-VL-PAG injection of capsaicin, and of the opposite effects of TRPV1 blockade with I-RTX, sug- gests that endovanilloid-induced activation of glutamate release in the RVM results in enhanced activity of anti-nociceptive OFF neurons. This might underlie the tonic control by TRPV1 of the nociceptive response to heat, observed here in both awake and anesthetized rats.

Our data with capsaicin agree with the study by Palazzo et al. (2002), in which capsaicin injected into the PAG (1-6 nmol/rat) increased the latency of nociceptive responses in a way sensitive to antagonists of NMDA or metabotropic glutamate receptor subtypes 1 and 5. However, McGaraughty et al. (2003) reported that capsaicin $(10 \mathrm{nmol} / \mathrm{rat})$ injected into the dorsolateral (DL) PAG induces hyperalgesia followed by delayed analgesia, the latter possibly caused by TRPV1 desensitization. The different PAG region investigated by these authors, and the subsequent activation/desensitization of another subset of TRPV1-espressing neurons, which stimulate the inhibitory PAG GABAergic interneurons impinging on anti-nociceptive excitatory PAG output neurons (for review, see Rea et al., 2007), might account for the observed different responses. Interestingly, capsaicin did cause here a second phase of glutamate release in the RVM, which correlated with anti-nociception in the plantar test and might be attributable, in part, to the desensitization mechanism hypothesized by McGaraughty et al. (2003). Accordingly, because one does not expect endogenous ligands to tonically desensitize their receptors under normal conditions, I-RTX, which acts by counteracting endovanilloid activity, did not cause a second negative peak of glutamate in microdialysates, nor did it cause a second phase of nociception. We also observed a very small and monophasic stimulation or inhibition of GABA release into the RVM after intra-VL-PAG injection of capsaicin or I-RTX, respectively. As TRPV1 is primarily coupled to glutamate release in the substantia nigra, locus ceruleus, nucleus tractus solitarius and paraventricular nucleus (Sasamura et al., 1998; Doyle et al., 2002; Marinelli et al., 2002, 2003, 2007; Jin et al., 2004; Li et al., 2004; Xing and Li, 2007), we believe that these effects are an indirect consequence of the modulation of glutamatergic neurons. RVM GABA release might be triggered by stimulation of glutamate receptors on RVM GABAergic interneurons, or on the aforementioned pronociceptive and desensitizable VL-PAG neurons, which also impinge on output inhibitory neurons (Rea et al., 2007). Interestingly, a TRPV1- and glutamate-mediated indirect stimulatory effect of GABAergic neurons was shown to occur in another region of the brainstem, the rat dorsal motor nucleus of the vagus (DMNV) (Derbenev et al., 2006).

Compared with the experiments in awake rats, a slightly higher dose of I-RTX ( $1 \mathrm{vs} 0.5 \mathrm{nmol} / \mathrm{rat}$ ) had to be used to observe changes in either RVM cell activities or thermoceptive thresholds (tail flick test) in anesthetized rats. Such decrease in I-RTX potency in anesthetized animals might be attributable to (1) propofol-induced enhancement on GABAergic tone (Orser et al., 1994; Davies et al., 1997), which at the PAG level is critical for the fine-tuning modulation of pain threshold (Moreau and Fields, 1986), and (2) the fact that propofol might enhance per se the tissue levels of the endovanilloid anandamide by inhibiting anandamide hydrolysis (Patel et al., 2003). However, although the pattern of the obtained results on the ongoing and tail flickrelated $\mathrm{ON}$ and $\mathrm{OFF}$ cell activity and tail flick latencies might be affected by anesthesia, we decided to use the classical methodology described by Fields et al. (1983), which is still considered the golden standard for in vivo electrophysiological recordings.

Our study does not provide direct evidence for the functional activity of TRPV1 receptors (in terms of their coupling to elevation of intracellular $\mathrm{Ca}^{2+}$ or to excitatory currents measured by 
patch clamp techniques) in isolated VLPAG neurons. Recent studies disputed the functional significance of TRPV1 receptors in the hippocampus (Kofalvi et al., 2006; Benninger et al., 2007). However, TRPV1 receptors coupled to elevation of intracellular $\mathrm{Ca}^{2+}$ were described in primary cultures of rat mesencephalic neurons (Kim et al., 2005), and patch-clamp measurements demonstrated the coupling of TRPV1 to postsynaptic excitatory currents in various mesencephalic (Marinelli et al., 2005, 2007) and brainstem [in the DMNV and DL-PAG (Derbenev et al., 2006; Xing and Li, 2007)] neurons. Therefore, whereas caution is needed when interpreting our electrophysiological and microdialysis data, they do suggest that functional TRPV1 receptors are present in VL-PAG neurons, although only indirectly and in view of previous findings.

We also identified here TRPV1 immunoreactivity (ir) in several cell bodies in both the VL-PAG and RVM. In line with previous studies (Cristino et al., 2006; Maione et al., 2006b), TRPV1 was mostly observed in the cytosol and cell membranes, possibly including presynaptic processes. In agreement with early studies on glutamatergic and GABAergic fiber distribution in the PAG (Williams and Beitz, 1990; Azkue et al., 1998), we observed a net of VGLUT1-ir and VGAT-ir terminals surrounding TRPV1 positive cells in the VL-PAG, strongly suggesting the existence of glutamatergic and GABAergic input on all these neurons. Also in the RVM, intense VGAT-ir and VGLUT1-ir fibers were found around somas that were clearly TRPV1-expressing. In both regions several TRPV1-ir neurons seem to be also glutamatergic as suggested by: 1) the presence in TRPV1-expressing neurons in the VLPAG of mGluR7-ir, a nonspecific albeit preferential marker of glutamatergic neurons (Somogyi et al., 2003), and of MOR afferents, which in this region mostly innervate NMDA receptor expressing antinociceptive glutamatergic neurons (Commons et al., 1999, 2000); 2) the colocalization of TRPV1 in the somas of several RVM neurons not only with mGluR7 and MOR but also VGLUT1. These data support the hypothesis that the increase and decrease of glutamate release observed in the RVM after intra-VL-PAG injection of capsaicin/I-RTX, which correlate with activation and inhibition of RVM OFF neurons, are attributable to activation and inhibition of TRPV1-expressing glutamatergic neurons.

The PAG receives neuronal input from the somatosensory cortex and anterior
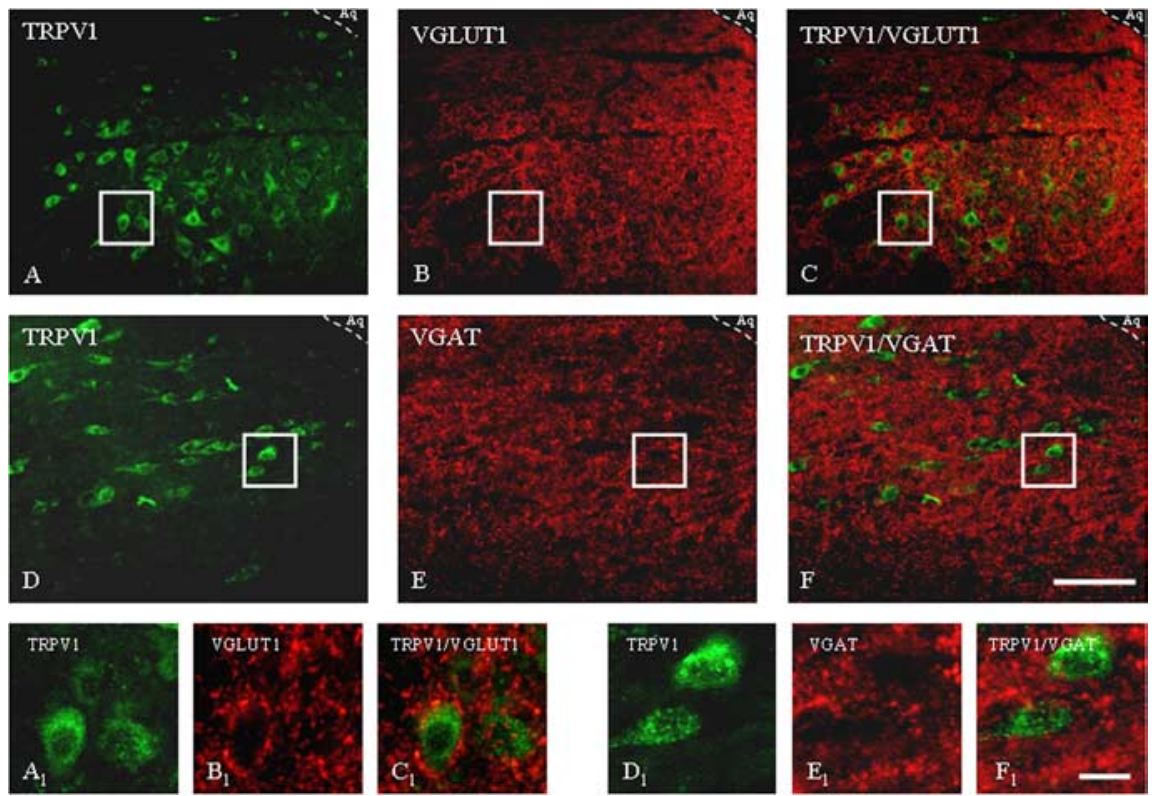

Figure 7. Immunohistochemical localization of TRPV1 receptors and VGLUT1 $(\boldsymbol{A}-\boldsymbol{C})$ and TRPV1 receptors and VGAT $(\boldsymbol{D}-\boldsymbol{F})$ in rat ventrolateral PAG as determined by the immunofluorescence technique. $\boldsymbol{A}-\boldsymbol{C}$, General view of the immunoreactive distribution in the ventrolateral subregion of the PAG of TRPV1 $(\boldsymbol{A})$, VGLUT1 $(\boldsymbol{B})$, and TRPV1/VGLUT1 (merged image) $(\boldsymbol{C}) . \boldsymbol{A}_{\boldsymbol{1}}-\boldsymbol{C}_{\boldsymbol{1}}$, High magnification of respective boxed areas of $\boldsymbol{A}-\boldsymbol{C}$. Note the dense TRPV1 receptor immunolabeling in cellular cytoplasm and processes (in green) and nerve terminals labeled for VGLUT1 (in red). $\boldsymbol{D}-\boldsymbol{F}$, General view of the immunoreactive distribution in the ventrolateral subregion of the PAG of TRPV1 $(\boldsymbol{D}), \operatorname{VGAT}(\boldsymbol{E})$, and TRPV1/VGAT (merged image) $(\boldsymbol{F})$. $\boldsymbol{D}_{\boldsymbol{1}}-\boldsymbol{F}_{\boldsymbol{1}}$, High magnification of respective boxed areas of $\boldsymbol{D}-\boldsymbol{F}$. Note the dense TRPV1 receptor immunolabeling in cytoplasm on cell bodies and neuronal processes (in green) and terminals labeled for VGAT (in red). Aq, Lumen of aqueduct. Scale bars: $\boldsymbol{A}-\boldsymbol{F}, 80 \mu \mathrm{m} ; \boldsymbol{A}_{\boldsymbol{1}}-\boldsymbol{F}_{\boldsymbol{1}}, 20 \mu \mathrm{m}$. Images are representative of those obtained in nine sections per rat.
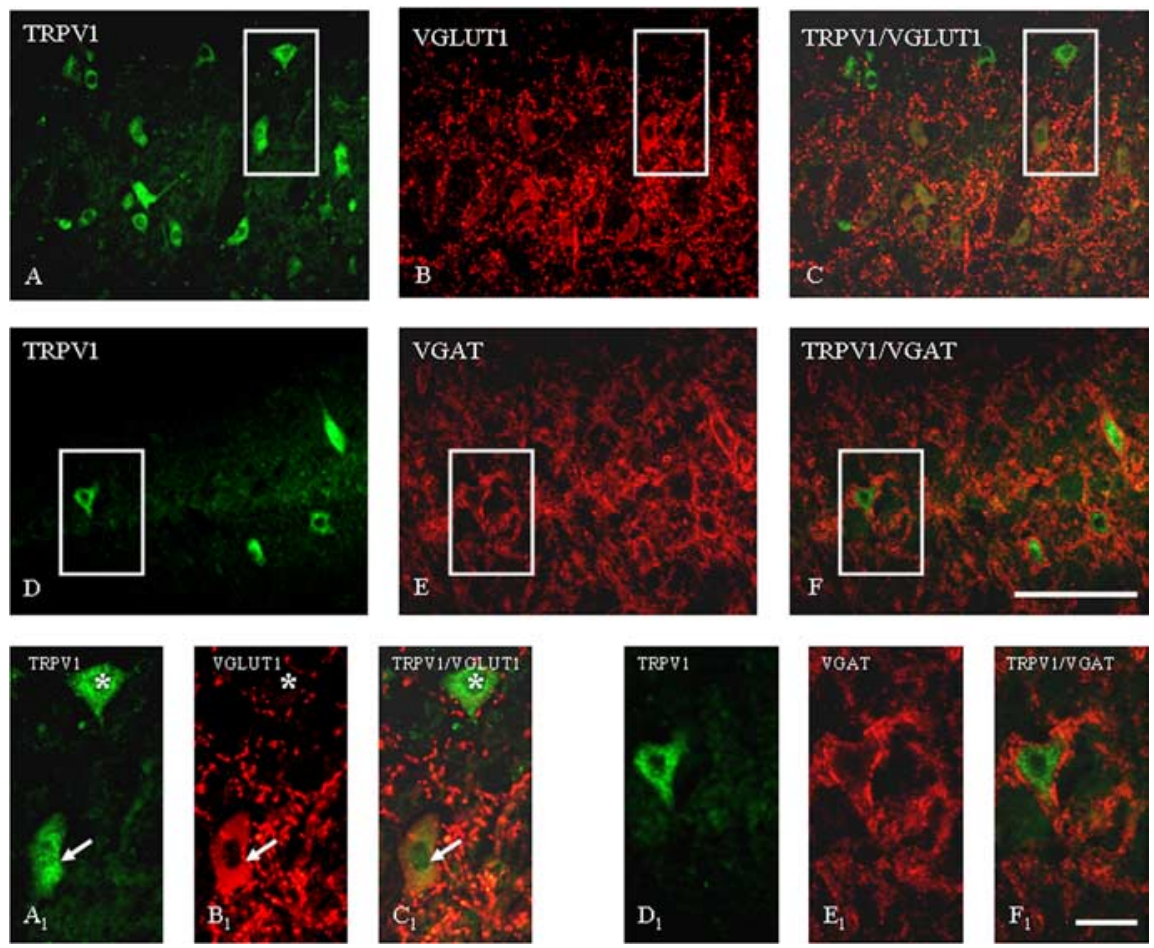

Figure 8. Micrographs demonstrating fluorescent staining of neurons in the RVM for TRPV1 receptor and VGLUT1 ( $A-C)$ and for TRPV1 receptor and VGAT ( $\boldsymbol{D}-\boldsymbol{F})$. $\boldsymbol{A}-\boldsymbol{C}$, Overview of the RVM region examined for TRPV1 and VGLUT1 localization; solid line box marks the region shown in $\boldsymbol{A}_{\boldsymbol{1}}-\boldsymbol{C}_{\boldsymbol{1}}$. Note that some TRPV1-labeled cells are surrounded by VGLUT1-positive nerve terminals (asterisk), whereas other cells are positive for both TRPV1 and VGLUT1 (arrows). $\boldsymbol{D}-\boldsymbol{F}$, Note constant TRPV1 labeling of cell membranes and cytoplasm in the RVM $\left(\boldsymbol{D}, \boldsymbol{D}_{\boldsymbol{1}}\right)$ and VGAT-positive terminals $\left(\boldsymbol{E}_{,} \boldsymbol{E}_{\boldsymbol{1}}\right)$ surrounding TRPV1-positive cells $\left(\boldsymbol{F}_{\boldsymbol{1}} \boldsymbol{F}_{\boldsymbol{1}}\right)$. Scale bar: $\boldsymbol{A}-\boldsymbol{F}, 60 \mu \mathrm{m} ; \boldsymbol{A}_{\boldsymbol{1}}-\boldsymbol{F}_{\boldsymbol{1}}, 15 \mu \mathrm{m}$. Images are representative of those obtained in nine sections per rat. 

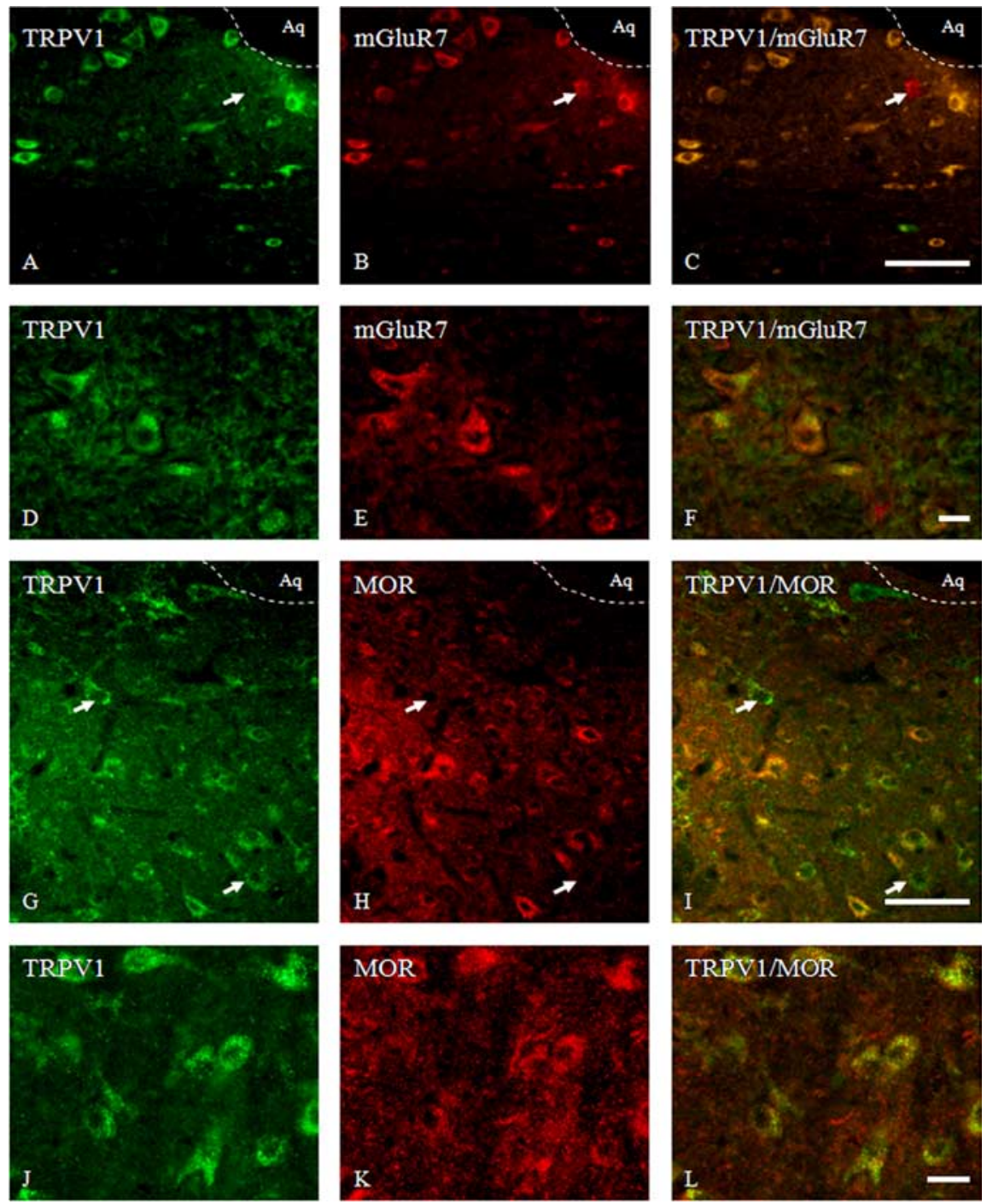

Figure 9. Photomicrographs of coronal sections through the ventrolateral PAG showing the same area immunolabeled for TRPV1 in green, $\mathrm{mGluR7}$ or $\mu$ opioid receptor (MOR) in red, and both in yellow in the merged images; and in the RVM representing neurons marked for TRPV1 (green) and mGluR7 (red) and merged images (yellow). $\boldsymbol{A}-\boldsymbol{C}$, Double immunofluorescence for TRPV1 and mGluR7 in the ventrolateral PAG. Note colocalization of TRPV1 and mGluR7 in the vast majority of neurons; just a few cells were only mGluR7 positive (arrow). D-F, Intense cytoplasmic localization for TRPV1 and mGluR7 on cell bodies of RVM neurons. G-I, Double immunofluorescence for TRPV1 and MOR in the ventrolateral PAG region showing TRPV1 distribution with postsynaptic MOR (yellow cells) in the majority of neurons stained, although some cells were also simply TRPV1-ir (arrows). J-L, Strong cytoplasmic colocalization for TRPV1 and MOR in a vast majority of cell bodies of RVM neurons. Aq, Lumen of aqueduct. Scale bars: $\boldsymbol{A}-\mathbf{C}, \mathbf{G}-\mathbf{I}, 80 \mu \mathrm{m} ; \mathbf{D}-\boldsymbol{F}, \mathbf{J}-\mathbf{L}, 15 \mu \mathrm{m}$. Images are representative of those obtained in nine sections per rat.

cingulate cortex (ACC), two cortical and limbic structures involved in the processing of pain (Calejesan et al., 2000; Millan, 2002; Tang et al., 2005), and activation of TRPV1 evokes glutamate release from cortical slices (Sasamura et al., 1999). Steenland et al. (2006) showed that capsaicin application to the ACC increases the firing frequency of some neurons but depresses that of others. Furthermore, Xing and Li (2007) recently reported a regulatory action of TRPV1 on glutamatergic activity in the DLPAG, whereby, by increasing synaptic glutamate release in the PAG, and activating both NMDA and non-NMDA receptors, this channel amplifies the firing frequency of excitatory DL-PAG neurons (Xing and Li, 2007). Our present data complement these previous observations and indicate that glutamatergic VL-PAG neurons controlling in a direct way the spontaneous activity of RVM OFF cells are also stimulated by TRPV1 channels. The results obtained with a selective TRPV1 antagonist suggest that this important brainstem descending pain pathway is tonically regulated by endovanilloids. Although additional studies are required to understand the exact role of TRPV1 in the supraspinal control of pain, our findings might open new avenues for the development of analgesic therapies (Szallasi et al., 2006).

\section{References}

Azkue JJ, Mateos JM, Elezgarai I, Benitez R, Lazaro E, Streit P, Grandes P (1998) Glutamate-like immunoreactivity in ascending spinofugal afferents to the rat periaqueductal grey. Brain Res 790:74-81.

Basbaum AI, Fields HL (1984) Endogenous pain control systems: brainstem spinal pathways and endorphin circuitry. Annu Rev Neurosci 7:309-338.

Behbehani MM (1995) Functional characteristics of the midbrain periaqueductal gray. Prog Neurobiol 46:575-605.

Behbehani MM, Fields HL (1979) Evidence that an excitatory connection between the periaqueductal gray and nucleus raphe magnus mediates stimulation produced analgesia. Brain Res 170:85-93.

Benninger F, Freund TF, Hajos N (2007) Control of excitatory synaptic transmission by capsaicin is unaltered in TRPV (1) vanilloid receptor knockout mice. Neurochem Int, in press.

Biggs CS, Pearce BR, Fowler LJ, Whitton PS (1992) The effect of sodium valproate on extracellular GABA and other amino acids in the rat ventral hippocampus: an in vivo microdialysis study. Brain Res 594:138-142.

Calejesan AA, Kim SJ, Zhuo M (2000) Descending facilitatory modulation of a behavioral nociceptive response by stimulation in the adult rat anterior cingulate cortex. Eur J Pain 4:83-96.

Caterina MJ, Schumacher MA, Tominaga M, Rosen TA, Levine JD, Julius D (1997) The capsaicin receptor: a heat-activated ion channel in the pain pathway. Nature 389:816-824.

Caterina MJ, Leffler A, Malmberg AB, Martin WJ, Trafton J, Petersen-Zeitz KR, Koltzenburg M, Basbaum AI, Julius D (2000) Impaired nociception and pain sensation in mice lacking the capsaicin receptor. Science 288:306-313.

Chu CJ, Huang SM, De Petrocellis L, Bisogno T, Ewing SA, Miller JD, Zipkin RE, Daddario N, Appendino G, Di Marzo V, Walker JM (2003) N-oleoyldopamine, a novel endogenous capsaicin-like lipid that produces hyperalgesia. J Biol Chem 278:13633-13639.

Commons KG, van Bockstaele EJ, Pfaff DW (1999) Frequent colocalization of mu opioid and NMDA-type glutamate receptors at postsynaptic sites in periaqueductal gray neurons. J Comp Neurol 408:549-559.

Commons KG, Aicher SA, Kow LM, Pfaff DW (2000) Presynaptic and postsynaptic relations of mu-opioid receptors to gamma-aminobutyric acid-immunoreactive and medullary-projecting periaqueductal gray neurons. J Comp Neurol 419:532-542.

Cristino L, de Petrocellis L, Pryce G, Baker D, Guglielmotti V, Di Marzo V (2006) Immunohistochemical localization of cannabinoid type 1 and vanilloid transient receptor potential vanilloid type 1 receptors in the mouse brain. Neuroscience 139:1405-1415.

Cui M, Honore P, Zhong C, Gauvin D, Mikusa J, Hernandez G, Chandran P, Gomtsyan A, Brown B, Bayburt EK, Marsh K, Bianchi B, McDonald H, Niforatos W, Neelands TR, Moreland RB, Decker MW, Lee CH, Sullivan JP, Faltynek CR (2006) TRPV1 receptors in the CNS play a key role in 
broad-spectrum analgesia of TRPV1 antagonists. J Neurosci 26:9385-9393.

Davies PA, Hanna MC, Hales TG, Kirkness EF (1997) Insensitivity to anaesthetic agents conferred by a class of GABA(A) receptor subunit. Nature 385:820-823.

Davis JB, Gray J, Gunthorpe MJ, Hatcher JP, Davey PT, Overend P, Harries MH, Latcham J, Clapham C, Atkinson H, Hughes SA, Rance K, Grau E, Harper AJ, Pugh PL, Rogers DC, Bingham S, Randall A, Sheardown SA (2000) Vanilloid receptor-1 is essential for inflammatory thermal hyperalgesia. Nature 405:183-187.

Davis KE, Straff DJ, Weinstein EA, Bannerman PG, Correale DM, Rothstein JD, Robinson MB (1998) Multiple signaling pathways regulate cell surface expression and activity of the excitatory amino acid carrier 1 subtype of Glu transporter in C6 glioma. J Neurosci 18:2475-2485.

Derbenev AV, Monroe MJ, Glatzer NR, Smith BN (2006) Vanilloidmediated heterosynaptic facilitation of inhibitory synaptic input to neurons of the rat dorsal motor nucleus of the vagus. J Neurosci 26:9666-9672.

Doyle MW, Bailey TW, Jin YH, Andresen MC (2002) Vanilloid receptors presynaptically modulate cranial visceral afferent synaptic transmission in nucleus tractus solitarius. J Neurosci 22:8222-8229.

Fields HL (2000) Pain modulation: expectation, opioid analgesia and virtual pain. Prog Brain Res 122:245-253.

Fields HL (2004) State-dependent opioid control of pain. Nat Rev Neurosci 5:565-575.

Fields HL, Bry J, Hentall I, Zorman G (1983) The activity of neurons in the rostral medulla of the rat during withdrawal from noxious heat. J Neurosci 3:2545-2552.

Fields HL, Heinricher MM, Mason P (1991) Neurotransmitters in nociceptive modulatory circuits. Annu Rev Neurosci 14:219-245.

Fields HL, Malick A, Burstein R (1995) Dorsal horn projection targets of $\mathrm{ON}$ and OFF cells in the rostral ventromedial medulla. J Neurophysiol 74:1742-1759.

Fields HL, Basbaum AI, Heinricher MM (2005) Central nervous system mechanisms of pain modulation. In: Wall and Melzack's textbook of pain, Ed 5 (Mc Mahon S, Koltzenburg M, eds). Edinburgh: Churchill Livingstone.

Fournier KM, Gonzalez MI, Robinson MB (2004) Rapid trafficking of the neuronal glutamate transporter, EAAC1: evidence for distinct trafficking pathways differentially regulated by protein kinase $\mathrm{C}$ and platelet-derived growth factor. J Biol Chem 279:34505-34513.

Gebhart GF, Sandkuhler J, Tralhammer JG, Zimmermann M (1984) Inhibition in the spinal cord of nociceptive information by electrical stimulation and morfine microinjection at identical sites in midbrain of the cat. J Neurophysiol 51:75-89.

Harris RM, Hendrickson AE (1987) Local circuit neurons in the rat ventrobasal thalamus-a GABA immunocytochemical study. Neuroscience 21:229-236.

Heinricher MM, Tortorici V (1994) Interference with GABA transmission in the rostral ventromedial medulla: disinhibition of off-cells as a central mechanism in nociceptive modulation. Neuroscience 63:533-546.

Huang SM, Bisogno T, Trevisani M, Al-Hayani A, De Petrocellis L, Fezza F, Tognetto M, Petros TJ, Krey JF, Chu CJ, Miller JD, Davies SN, Geppetti P, Walker JM, Di Marzo V (2002) An endogenous capsaicin-like substance with high potency at recombinant and native vanilloid VR1 receptors. Proc Natl Acad Sci USA 99:8400-8405.

Hwang SW, Chom H, Kwak J, Lee SY, Kang CJ, Jung J, Cho S, Min KH, Suh YG, Kim D, Oh U (2000) Direct activation of capsaicin receptors by products of lipoxygenases: endogenous capsaicin-like substances. Proc Natl Acad Sci USA 97:6155-6160.

Jin YH, Bailey TW, Li BY, Schild JH, Andresen MC (2004) Purinergic and vanilloid receptor activation releases glutamate from separate cranial afferent terminals in nucleus tractus solitarius. J Neurosci 24:4709-4717.

Kalyuzhny AE, Arvidsson U, Wu W, Wessendorf MW (1996) $\mu$-Opioid and $\delta$-opioid receptors are expressed in brainstem antinociceptive circuits: studies using immunocytochemistry and retrograde tract-tracing. J Neurosci 16:6490-6503.

Kim SR, Lee DY, Chung ES, Oh UT, Kim SU, Jin BK (2005) Transient receptor potential vanilloid subtype 1 mediates cell death of mesencephalic dopaminergic neurons in vivo and in vitro. J Neurosci 25:662-671.

Kofalvi A, Oliveira CR, Cunha RA (2006) Lack of evidence for functional
TRPV1 vanilloid receptors in rat hippocampal nerve terminals. Neurosci Lett 403:151-156.

Li DP, Chen S-R, Pan H-L (2004) VR 1 receptor activation induces glutamate release and postsynaptic firing in the paraventricular nucleus. J Neurophysiol 92:1807-1816.

Liapi A, Wood JN (2005) Extensive co-localization and heteromultimer formation of the vanilloid receptor-like protein TRPV2 and the capsaicin receptor TRPV1 in the adult rat cerebral cortex. Eur J Neurosci 22:825-834.

Maione S, Starowicz K, Palazzo E, Rossi F, Di Marzo V (2006a) The endocannabinoid and endovanilloid systems and their interactions in neuropathic pain. Drug Dev Res 67:339-354.

Maione S, Bisogno T, de Novellis V, Palazzo E, Cristino L, Valenti M, Petrosino S, Guglielmotti V, Rossi F, Di Marzo V (2006b) Elevation of endocannabinoid levels in the ventrolateral periaqueductal grey through inhibition of fatty acid amide hydrolase affects descending nociceptive pathways via both cannabinoid receptor type 1 and transient receptor potential vanilloid type-1 receptors. J Pharmacol Exp Ther 316:969-982.

Maione S, De Petrocellis L, de Novellis V, Moriello AS, Petrosino S, Palazzo E, Rossi FS, Woodward DF, Di Marzo V (2007) Analgesic actions of $\mathrm{N}$-arachidonoyl-serotonin, a fatty acid amide hydrolase inhibitor with antagonistic activity at vanilloid TRPV1 receptors. Br J Pharmacol 150:766-781.

Marinelli S, Vaughan CW, Christie MJ, Connor M (2002) Capsaicin activation of glutamatergic synaptic transmission in the rat locus coeruleus in vitro. J Physiol (Lond) 543:531-540.

Marinelli S, Di Marzo V, Berretta N, Matias I, Maccarrone M, Bernardi G, Mercuri NB (2003) Presynaptic facilitation of glutamatergic synapses to dopaminergic neurons of the rat substantia nigra by endogenous stimulation of vanilloid receptors. J Neurosci 23:3136-3144.

Marinelli S, Pascucci T, Bernardi G, Puglisi-Allegra S, Mercuri NB (2005) Activation of TRPV1 in the VTA excites dopaminergic neurons and increases chemical- and noxious-induced dopamine release in the nucleus accumbens. Neuropsychopharmacology 30:864-870.

Marinelli S, Di Marzo V, Florenzano F, Fezza F, Viscomi MT, van der Stelt M, Bernardi G, Molinari M, Maccarrone M, Mercuri NB (2007) $\mathrm{N}$-arachidonoyl-dopamine tunes synaptic transmission onto dopaminergic neurons by activating both cannabinoid and vanilloid receptors. Neuropsychopharmacology 32:298-308.

McGaraughty S, Chu KL, Bitner RS, Martino B, El Kouhen R, Han P, Nikkel AL, Burgard EC, Faltynek CR, Jarvis MF (2003) Capsaicin infused into the PAG affects rat tail flick responses to noxious heat and alters neuronal firing in the RVM. J Neurophysiol 90:2702-2710.

Mezey E, Toth ZE, Cortright DN, Arzubi MK, Krause JE, Elde R, Guo A, Blumberg PM, Szallasi A (2000) Distribution of mRNA for vanilloid receptor subtype 1 (VR1), and VR1-like immunoreactivity, in the central nervous system of the rat and human. Proc Natl Acad Sci USA 97:3655-3660.

Millan MJ (2002) Descending control of pain. Prog Neurobiol 66:355-474.

Millan MJ, Członkowski A, Millan MH, Herz A (1987) Activation of periaqueductal grey pools of beta-endorphin by analgetic electrical stimulation in freely moving rats. Brain Res 407:199-203.

Moreau JL, Fields HL (1986) Evidences for GABA involvement in midbrain control of medullary neurons that modulate nociceptive transmission. Brain Res 397:37-46.

Orser BA, Wang LY, Pennefather PS, MacDonald JF (1994) Propofol modulates activation and desensitization of $\mathrm{GABA}_{\mathrm{A}}$ receptors in cultured murine hippocampal neurons. J Neurosci 14:7747-7760.

Palazzo E, de Novellis V, Marabese I, Cuomo D, Rossi F, Berrino L, Rossi F, Maione S (2002) Interaction between vanilloid and glutamate receptors in the central modulation of nociception. Eur J Pharmacol 439:69-75.

Patel S, Wohlfeil ER, Rademacher DJ, Carrier EJ, Perry LJ, Kundu A, Falck JR, Nithipatikom K, Campbell WB, Hillard CJ (2003) The general anesthetic propofol increases brain $N$-arachidonylethanolamine (anandamide) content and inhibits fatty acid amide hydrolase. Br J Pharmacol 139:1005-1013.

Paxinos G, Watson C (1986) The rat brain in stereotaxic coordinates. London: Academic.

Rea K, Roche M, Finn DP (2007) Supraspinal modulation of pain by cannabinoids: the role of GABA and glutamate. Br J Pharmacol 152:633-648.

Roberts JC, Davis JB, Benham CD (2004) [3H]Resiniferatoxin autoradiog- 
raphy in the CNS of wild-type and TRPV1 null mice defines TRPV1 (VR-1) protein distribution. Brain Res 995:176-183.

Ross RA, Coutts AA, McFarlane SM, Anavi-Goffer S, Irving AJ, Pertwee RG, MacEwan DJ, Scott RH (2001) Actions of cannabinoid receptor ligands on rat cultured sensory neurones: implications for antinociception. Neuropharmacology 40:221-232.

Sanchez JF, Krause JE, Cortright DN (2001) The distribution and regulation of vanilloid receptor VR1 and VR1 5' splice variant RNA expression in rat. Neuroscience 107:373-381.

Sandkuhler J, Gebhart GF (1984) Relative contributions of the nucleus raphe magnus and adjacent medullary reticular formation to the inhibition by stimulation in the periaqueductal grey of a spinal nociceptive reflex in the pentobarbital-anaesthetized rat. Brain Res 305:77-87.

Sasamura T, Kuraishi Y (1999) Peripheral and central actions of capsaicin and VR1 receptor. Jpn J Pharmacol 80:275-280.

Sasamura T, Sasaki M, Tohda C, Kuraishi Y (1998) Existence of capsaicinsensitive glutamatergic terminals in rat hypothalamus. NeuroReport 9:2045-2048.

Somogyi P, Dalezios Y, Lujan R, Roberts JD, Watanabe M, Shigemoto R (2003) High level of mGluR7 in the presynaptic active zones of select populations of GABAergic terminals innervating interneurons in the rat hippocampus. Eur J Neurosci 17:2503-2520.

Starowicz K, Nigam S, Di Marzo V (2007) Biochemistry and pharmacology of endovanilloids. Pharmacol Ther 114:13-33.
Steenland HW, Ko SW, Wu LJ, Zhuo M (2006) Hot receptors in the brain. Mol Pain 2:34.

Szallasi A, Cruz F, Geppetti P (2006) TRPV1: a therapeutic target for novel analgesic drugs? Trends Mol Med 12:545-554.

Tang J, Ko S, Ding HK, Qiu CS, Calejesan AA, Zhuo M (2005) Pavlovian fear memory induced by activation in the anterior cingulated cortex. Mol Pain 1:6.

Toth A, Boczan J, Kedei N, Lizanecz E, Bagi Z, Papp Z, Edes I, Csiba L, Blumberg PM (2005) Expression and distribution of vanilloid receptor 1 (TRPV1) in the adult rat brain. Brain Res Mol Brain Res 135:162-168.

Westlund KN, Bowker RM, Ziegler MG, Coulter JD (1983) Noradrenergic projections to the spinal cord of the rat. Brain Res 263:15-31.

Williams FG, Beitz AJ (1990) Ultrastructural morphometric analysis of GABA-immunoreactive terminals in the ventrocaudal periaqueductal grey: analysis of the relationship of GABA terminals and the GABAA receptor to periaqueductal grey-raphe magnus projection neurons. J Neurocytol 19:686-696.

Xing J, Li J (2007) TRPV1 receptor mediates glutamatergic synaptic input to dorsolateral periaqueductal gray (dl-PAG) neurons. J Neurophysiol 97:503-511.

Zygmunt PM, Petersson J, Andersson DA, Chuang H, Sørgård M, Di Marzo V, Julius D, Högestätt ED (1999) Vanilloid receptors on sensory nerves mediate the vasodilator action of anandamide. Nature 400:452-457. 